$\begin{array}{ll} & \text { Etnográfica } \\ \text { etnográfica } & \text { Revista do Centro em Rede de Investigação em }\end{array}$

Antropologia

vol. $20(1) \mid 2016$

Vol. 20 (1)

\title{
Etnobotánica del Darién Caribe colombiano: los frutos del bosque
}

Ethnobotany of the Colombian Caribbean Darien: wild fruits

\section{Lizeth Marelly Álvarez Salas, Aída Gálvez Abadía y Julio César \\ Salazar Zapata}

\section{(2) OpenEdition}

Journals

Edición electrónica

URL: https://journals.openedition.org/etnografica/4244

DOI: 10.4000/etnografica.4244

ISSN: 2182-2891

\section{Editor}

Centro em Rede de Investigação em Antropologia

\section{Edición impresa}

Fecha de publicación: 1 febrero 2016

Paginación: 193-193

ISSN: 0873-6561

\section{Referencia electrónica}

Lizeth Marelly Álvarez Salas, Aída Gálvez Abadía y Julio César Salazar Zapata, «Etnobotánica del

Darién Caribe colombiano: los frutos del bosque», Etnográfica [En línea], vol. 20 (1) | 2016, Publicado el 04 marzo 2016, consultado el 09 febrero 2022. URL: http://journals.openedition.org/etnografica/4244 ; DOI: https://doi.org/10.4000/etnografica.4244

Etnográfica is licensed under a Creative Commons Attribution-NonCommercial 4.0 International License. 


\section{Etnobotánica del Darién Caribe colombiano: los frutos del bosque}

\section{Lizeth Marelly Álvarez Salas, Aída Gálvez Abadía y Julio César Salazar Zapata}

El texto presenta las relaciones que establecen los habitantes de San Francisco de Asís, en el Darién Caribe colombiano, con el entorno ecológico, en cuanto al aprovechamiento de frutos silvestres y a la introducción de especies frutales como estrategias de autoabastecimiento. Desde una visión etnobotánica con enfoque agroecológico, se observan las transformaciones del ecosistema, las prácticas en contravía de las tradiciones y del cuidado del ambiente y las dificultades surgidas a nivel agrícola por causa de aquellas. En un contexto multicultural de afrodescendientes, campesinos de las sabanas costeñas e interioranos del país, se desarrollan procesos de conservación atravesados por la ausencia del Estado, la economía ilegal y el relevo generacional con sus expectativas y contradicciones.

PALABRAS CLAVE: frutas del Darién, transformaciones socioecológicas, multiculturalismo, conocimientos locales, etnobotánica.

Ethnobotany of the Colombian Caribbean Darien: wild fruits - The article presents the relationships established between the residents of San Francisco de Asís, in the Colombian Caribbean Darien, and their ecological context, regarding the use of wild fruits and introduced fruit species as strategies of self-sufficiency. From an ethnobotanical perspective and with an agroecological approach, it reports and discusses observed ecosystem changes, as well as practices that counter traditional environmental management, and agricultural challenges brought up by those changes. In a multicultural context composed of African descendents, peasants from coastal savannas and Andean migrants, conservation processes involve the absence of the State, illegal economy and generational shifts that reveal different expectations and contradictions.

KEYWORDS: fruits of the Darien, socioecological transformations, multiculturalism, local knowledge, ethnobotany.

ÁLVAREZ SALAS, Lizeth Marelly (lizethalvarezsalas@gmail.com) - Universidad de Antioquia, Colombia.

GÁlVEZ ABADÍA, Aída (agalvez34@gmail.com) - Universidad de Antioquia, Colombia.

SALAZAR ZAPATA, Julio César (abulrojo@yahoo.com) - Universidad de Antioquia, Colombia. 


\section{INTRODUCCIÓN}

Este artículo presenta los aspectos socioecológicos alrededor del aprovechamiento de especies frutales silvestres fomentadas y cultivadas en el corregimiento de San Francisco de Asís, localizado a $7^{\circ} 25^{\prime}$ norte, $74^{\circ} 26^{\prime}$ oeste sobre el mar Caribe en la vertiente occidental del golfo de Urabá, y adscrito al municipio de Acandí al norte del departamento del Chocó como parte de los territorios constitutivos del Darién (Uribe et al. 1999). ${ }^{1}$ El lugar de estudio es conocido localmente como San Pacho y tiene un área aproximada de 86.900 ha (DANE 2005), con una población estimada en 1300 habitantes compuesta por afrodescendientes, mestizos cordobeses o "chilapos" ${ }^{2}$ y un grupo menor de interioranos del país o "paisas", asentados en la cabecera del corregimiento y en áreas rurales (Salazar Zapata 2012). ${ }^{3}$ Con una escasa influencia sobre la zona, Quibdó, capital del departamento, está localizada a $558 \mathrm{~km}$ vía río Atrato, mientras que el municipio de Turbo (Antioquia), en el Golfo de Urabá, dista $85 \mathrm{~km}$ vía marítima y mantiene una influencia decisiva en el corregimiento. Su cercanía ha favorecido el desarrollo de relaciones comerciales, no sólo con San Pacho sino también con otras localidades ubicadas en el Caribe chocoano.

Las comunidades rurales del Darién Caribe colombiano disponen de una gran diversidad florística propia del bosque húmedo tropical (Castro, Abadía y Pino 2004; García 2002), aprovechada en usos medicinales (Fonnegra, Botero y Jiménez 2000; Caicedo 2004; Zuluaga 2002), alimenticios (Becerra,

I Los autores agradecen la ayuda financiera del CODI Universidad de Antioquia para la realización del proyecto de mediana cuantía del cual se deriva este artículo, al Proyecto de Sostenibilidad de Grupos de Investigación 2013-2014 de la Vicerrectoría de Investigación de la Universidad de Antioquia, a la Fundación Aurelio Llano Posada y al apoyo de Sostenibilidad 2007-2008 otorgado al grupo RCS dentro del cual Julio Salazar Zapata realizó su proyecto indicado en su libro, a la Sociedad Científica Latinoamericana de Agroecología SOCLA y al Doctorado en Agroecología de la Facultad de Ciencias Agrarias de la Universidad de Antioquia. Los autores elevan su más sincero reconocimiento a la población de San Francisco de Asís, salvaguardas del bosque y de la magia, origen de profundos aprendizajes. Agradecemos también el apoyo de Cecilia Salas y de Federico Ortiz.

2 "Chilapo" es un apelativo generalizado en el noroccidente colombiano para referirse a la gente originaria de la llanura Caribe. El término procede del lenguaje de los aserradores y designa los restos que quedan de un tronco luego de obtener bloques centrales, homogéneos y finos; son pues sobrantes no utilizados pese a haber contribuido al crecimiento del árbol (Molano y Ramírez 1996: 23).

3 Su principal componente cultural es mestizo, proveniente del interior de Colombia, especialmente de Antioquia, Valle del Cauca y el Eje cafetero. Todos ellos han habitado preferentemente la zona rural del corregimiento, desde mediados de la década del 60. También existe una población de afrodescendientes (DANE 2005), proveniente de la zona norte del Caribe colombiano; esta población habita la cabecera del corregimiento, junto a los campesinos "chilapos". Tanto los habitantes afrocolombianos como los "chilapos", sus descendientes y los hijos de los "paisas", que han nacido y/o se han criado allí, se denominan localmente como "nativos" (Roldán 2012). 
Escobar y Serna 2004; Franco 1996), ornamentales (García et al. 2002), mágico-religiosos (Fonnegra, Botero y Jimenez 2010) y artesanales (Feuillet, Macias y Chito 2011). La relación entre biodiversidad y su aprovechamiento cultural aparece en la actualidad como una preocupación no sólo para la academia agroecológica, sino también para los locales que dependen del uso y aprovechamiento de los recursos de su entorno. La conciencia sobre la degradación ambiental, la pérdida de especies y el deterioro de la calidad de vida de las comunidades rurales ha llevado a ampliar e intensificar los estudios sobre espacios de interacción y de construcción alternativa que repercutan en el mejoramiento de contextos socioecológicos.

Las estrategias económicas locales se soportaron hasta mediados de la década del 2000 en la explotación de maderas, la pesca artesanal y en los cultivos de subsistencia (Salazar Zapata 2012; Álvarez-Salas y Gálvez-Abadía 2014). A su vez, se han desarrollado estrategias de ecoturismo local a partir de procesos de participación comunitaria (Roldán 2012), sin embargo este proyecto hoy está paralizado dadas las dificultades en los procesos de organización social, el retiro de ayudas a cargo de entidades externas y la poca visibilidad de San Francisco como destino ecoturístico. La actual oferta de bienes y servicios ligados a la atención de visitantes la suplen hoteles y restaurantes de particulares mediante la autogestión y el voz a voz. En lo anterior, es común ver cómo la oferta de especies alimenticias locales es atractiva para el turista de aventura, como las frutas silvestres que son consideradas parte de la oferta gastronómica para los visitantes. Uno de estos frutos ampliamente difundido en la región es el sietesabores (Diospyros blancoi A. DC), que se constituye como una de las especies emblemáticas en el área de estudio, gracias a su potencial nutricional (Álvarez-Salas 2014), aunado al halo de misterio que genera su delicioso sabor, que hace honor a su nombre. Sin embargo no reviste aún una importancia económica significativa en mercados situados por fuera de la localidad.

A pesar de este potencial, algunos habitantes - en especial la población más joven - se han vinculado a economías de orden ilegal articuladas al narcotráfico, fenómeno que ha desestimulado las labores agrícolas, pesqueras y turísticas. También se ha incentivado la migración a la localidad incrementando el número de habitantes y suscitando mayores presiones sobre los recursos, en especial las referidas a la extracción de madera y al uso creciente de arena de playa para la construcción de nuevas viviendas (Álvarez-Salas 2014). La incipiente agricultura no logra abastecer la demanda local de alimentos, por lo tanto, su introducción foránea, para cubrir necesidades del consumo alimentario de hogares y hoteles, es cada vez mayor.

Esta investigación, con enfoque agroecológico y etnobotánico, explora los saberes, las experiencias de los actores locales y las prácticas sociales alrededor de especies frutales del bosque y de aquellas fomentadas e introducidas en 
procesos de colonización. ${ }^{4}$ En particular, este estudio indaga por los conocimientos locales, que surgen informalmente a partir de la observación de los agroecosistemas (Sinclair y Walker 1999), mediante una combinación entre el sentido común, las interacciones sociales y la experiencia práctica de generaciones pasadas y presentes y su proyección al futuro, conocimiento acumulativo y dinámico que permite adaptarse a los cambios (Coles et al. 2011; Mora-Delgado 2009).

Investigaciones en la Amazonía, en India y en Tailandia han establecido las relaciones de dependencia de campesinos y agricultores con recursos alimenticios silvestres cosechados en el bosque, localizados cerca de las fuentes de agua, de los caminos y de las cabeceras de residencia (Martínez-Rodríguez 2009; Cruz-García 2006; Setalaphruk y Price 2007). Estas plantas favorecen la diversificación de la dieta, en su mayoría compuesta por cereales y tubérculos, tal como ocurre en San Francisco, el área de este estudio. El bosque constituyó una importante fuente de proteína a partir de la cacería de especies menores que incluyen aves y venados (Odocoileus virginianus tropicalis Cabrera), entre otras especies silvestres que ya no están disponibles, por encontrarse en zonas alejadas de los centros humanos. Aún se conserva la pesca de camarones de agua dulce y cangrejos (Cruz-García 2006; Somnasang, Rathakette y Rathanapanya 1987), constituyéndose en lugar de significativo aporte a la nutrición de poblaciones rurales, especialmente en zonas marginales (Martínez-Rodríguez 2009), como la zona de interés de este estudio. Pieroni y Price (2005) argumentan que estos recursos silvestres pueden contribuir al mantenimiento de la salud como alimentos funcionales o medicinales, al no estar contaminados con agroquímicos o antibióticos.

Sin embargo, esta dependencia de los recursos silvestres ha ido menguando paulatinamente, dadas las condiciones de deforestación que dan paso a la ganadería extensiva y los monocultivos, de acuerdo con las dinámicas de colonización activadas en las últimas décadas. Ante este panorama, las condiciones para un desarrollo sostenible se muestran inciertas, puesto que su conservación se mantiene en entredicho frente a las prácticas que afectan el ecosistema local.

El objetivo de este artículo es analizar la existencia de especies frutales en el corregimiento otrora consumidas por las poblaciones, pero en desuso debido a los cambios alimentarios que han ocurrido en la última década. A su vez, se observa cómo el carácter oral y práctico de los conocimientos locales vinculados a estas especies tiene hoy poca valoración por las generaciones más jóvenes, ante su resistencia a las labores agrícolas que han sido sustituidas por una economía de carácter monetario.

4 Es sabido que muchas investigaciones etnobotánicas se han desarrollado en sociedades amerindias (Hurtado et al. 2008), por lo tanto, los hallazgos son producto de una comprensión de los conocimientos tradicionales donde se incluyen valores culturales y creencias míticas (Zerda 2003). 


\section{MÉTODOS}

La agroecología como disciplina científica propone un nuevo enfoque para la comprensión de la realidad del sistema naturaleza-cultura desde el análisis de las relaciones socioecológicas que se desarrollan en agroecosistemas (Álvarez-Salas, Polanco-Echeverry y Ríos-Osorio 2014; Polanco-Echeverry, Álvarez-Salas e Ríos-Osorio 2015). En esta investigación, la unidad de análisis trasciende la parcela y delimita como agroecosistema el corregimiento de San Francisco de Asís en su extensión. Más allá de comprender cómo se efectúa la apropiación de los alimentos del bosque en las comunidades que allí habitan, se analizan las relaciones establecidas con el ecosistema mayor que lo contiene y las dinámicas sociopolíticas y culturales que lo afectan en forma directa o indirecta.

Esta investigación requirió un enfoque transdisciplinario de carácter sistémico propuesto por García (2006) y adaptado por Polanco-Echeverry, Álvarez-Salas e Ríos-Osorio (2015) en el cual se consideraron factores tales como: condiciones ecológicas, conocimientos de plantas silvestres para la alimentación humana y animal, usos del territorio, características socioculturales y económicas de la población, instituciones y programas exógenos. Para la identificación de las especies frutales del bosque se recurrió a métodos etnobotánicos con los que fue posible identificar no sólo la biología de los recursos forestales sino también los conocimientos, las creencias locales vinculadas a éstas (Alexiades 1996) y los usos ligados a procesos de transformación y conservación.

Se realizaron dos visitas de campo. La primera en enero de 2011 , con el propósito de hacer un reconocimiento del área a partir del registro escrito y fotográfico de las impresiones iniciales del lugar; se abordó a los pobladores mediante conversaciones incidentales, y se hicieron ajustes a las guías de campo. La temporada de terreno se desarrolló entre julio y diciembre de 2011. La aplicación del método etnográfico permitió la observación de lo que los sujetos hacen y dicen, a partir de lo que Malinowski (1973 [1922]) define como "el estar allí", donde la convivencia prolongada permitió aprender sobre las costumbres, las formas de ser y las formas de relación con su realidad. Aquí, se identificaron algunos aspectos contradictorios entre lo que los individuos dicen y lo que hacen, y por lo tanto, se visibilizó cómo en ocasiones los discursos difieren de las prácticas, factor relevante en investigaciones referidas al contexto del uso y manejo de los recursos naturales.

Se observaron las actividades cotidianas (Guber 2007: 23-40) relacionadas con el medio ambiente, se recogieron discursos sobre el saber etnobotánico, las formas de apropiación y las estrategias de conservación, sin dejar de lado el registro de actitudes de descuido al respecto del manejo de los recursos naturales. Se hizo el registro en diario de campo, se elaboraron 84 entrevistas semiestructuradas relacionadas con el uso y apropiación del bosque. Adicionalmente se realizaron 30 entrevistas en profundidad a interlocutores clave, cuyas 
edades oscilaban entre los 25 y los 62 años (muchas de ellas en el escenario del bosque). A partir de la totalidad de las entrevistas se extrajeron diez por cada grupo humano (afrodescendientes, chilapos y paisas). Diecisiete de las entrevistas se hicieron a mujeres y trece entrevistas a hombres.

Se obtuvieron sendos consentimientos informados en los que se declara la participación libre y espontánea de los interlocutores en el proyecto. El bosque se recorrió en compañía de uno de ellos siguiendo las técnicas de estudios socio-económicos y ambientales recomendadas para bosques tropicales (Turbay 2004). Las plantas silvestres para la alimentación humana y animal fueron identificadas in situ gracias al conocimiento local. Se hicieron registros fotográficos, se describieron las características botánicas principales y del hábitat, las cuales fueron incluidas en una ficha de colecta etnobotánica de elaboración personal, siguiendo los parámetros de Martin (1995). La clasificación taxonómica se realizó con la ayuda de expertos del Herbario de la Universidad de Antioquia. ${ }^{5}$ Los ejemplares analizados no fueron extraídos de su hábitat, a excepción de un ejemplar de sietesabores (Diospyros blancoi A. DC) el cual fue donado por el propietario de una parcela agrícola con título de propiedad sobre ésta.

La estadía en la localidad durante cinco meses permitió profundizar en las prioridades, en los conflictos internos y en las inquietudes alrededor de la alimentación según el punto de vista de los lugareños. Las entrevistas fueron transcritas, sistematizadas y ordenadas en 20 categorías de análisis en el programa ATLAS TI 6.0.

\section{Análisis sensorial del fruto sietesabores}

Durante el trabajo de campo, se constató la importancia del fruto de sietesabores en la alimentación local, sus potencialidades, las alternativas de aprovechamiento en la oferta gastronómica hotelera, donde se ofrece como un secreto gustativo que deberá ser develado por propios y extraños. Dada la importancia para los lugareños, se hizo un análisis sensorial de esta fruta (Diospyros blancoi) por petición de los interlocutores, quienes incluyeron estos datos como información adicional en su oferta gastronómica. ${ }^{6}$ Estos análisis fueron realizados en el Laboratorio de Salud Pública, Área de Análisis Fisicoquímico de la Facultad Nacional de Salud Pública y Facultad de Química Farmacéutica de la Universidad de Antioquia, bajo las Normas Técnicas Colombianas 3501 y 3929 y las Guías Técnicas Colombianas 165 y 226 de 2012. Se escogieron cinco unidades para caracterizar los descriptores de sabor del fruto. Este procedimiento se basa en el análisis de los atributos por separado, los cuales contribuyen a la

5 Para la identificación taxonómica se recurre a $<$ http://www.tropicos.org $>$ y $<$ http://www.gbif.org /dataset/23243164-c132-444d-a3a4-34662abb8305 >.

6 Se hizo la devolución de esta información conjuntamente con los resultados de análisis bromatológicos de este fruto publicados en Álvarez-Salas (2014). 
formación de una impresión total del producto. A su vez se identifica y evalúa la intensidad sensorial para estructurar la descripción del sabor. Esta intensidad es valorada por un panel de 16 jueces entrenados en análisis de sabor, textura y olor. La calificación es de 1 a 5 para todos los descriptores de sabor, excepto para la calidad general, en la que se utiliza una escala de 1 a 3 siendo 1 el más bajo y 3 el más alto. Para el ensayo se tuvo en cuenta condiciones como: tipo de luz artificial; humedad relativa al inicio de prueba: 61\%; humedad relativa al finalizar la prueba: $50 \%$; temperatura al inicio de prueba: $25^{\circ} \mathrm{C}$; temperatura final: $25^{\circ} \mathrm{C}$.

\section{RESULTADOS}

Las zonas de bosque localizadas en la jurisdicción del corregimiento de San Francisco de Asís asisten a un incremento en los procesos de deforestación en las últimas dos décadas, producto de la venta ilegal de madera y de la expansión ganadera (Álvarez-Salas y Gálvez-Abadía 2014). Este fenómeno, observado en toda la región del Darién Caribe colombiano, ha generado el descenso no solo de especies maderables, sino también la pérdida de especies frutales que fueron usadas como complemento nutricional de poblaciones humanas y de animales. Durante el trabajo de campo se identificaron dos grandes grupos de especies frutales para el consumo: las frutas silvestres y las frutas fomentadas o introducidas.

\section{Frutas silvestres}

Los pobladores del corregimiento de San Francisco de Asís reconocen 40 especies de frutas silvestres (ver tabla 1 ) que aún no han sido domesticadas ni fomentadas en sistemas productivos. Su consumo se restringe a las épocas de mayor fructificación entre los meses de febrero y junio (ver figura 1) cuando los habitantes disfrutan de la abundancia alimentaria; sin embargo, admiten que los procesos de deforestación del bosque y la introducción de alimentos de origen industrial, desde la localidad de Turbo (Antioquia) y desde la ciudad de Medellín, ha reducido significativamente su reproducción y consumo.

Las frutas están vinculadas a los hábitos de consumo de animales silvestres y su introducción a la dieta humana se basó en la repetición de las conductas alimentarias animales, en especial aquellas del mono cariblanco o capuchino (Cebus capucinus L.) y del mono aullador (Alouatta palliata Gray).

“[...] uno sabía cuáles frutos del monte eran buenos porque los animales las comían también, yo pienso: los animales no son bobos, ellos saben cuáles son las frutas gustositas y cuáles no. Entonces uno se ponía a ver cuáles eran las que elegían y cuáles dejaban, y esas buenas eran las que uno también elegía. Es que también hay mucha fruta mala, como venenosa, iqué día MA se puso a ensayar y casi se muere!" [ER, agosto de 2013] 


\section{Tabla 1}

\section{Frutos silvestres del corregimiento de San Francisco de Asís, en Acandi - Chocó}

\begin{tabular}{|c|c|c|c|c|}
\hline No & Nombre común & Nombre científico & Localización & $\begin{array}{c}\text { Parte } \\
\text { comestible }\end{array}$ \\
\hline \multirow{2}{*}{1} & \multirow{2}{*}{ Barbasco sicui } & \multirow{2}{*}{ Cordia bifurcata R. \& S. } & \multirow{2}{*}{ Bosque secundario } & Hojas \\
\hline & & & & Fruto \\
\hline 2 & Venturosa (2) & Lantana camara L.(3) & Bosque de sucesión temprana & Fruto \\
\hline 3 & Cafetillo o Jazmín & $\begin{array}{l}\text { Faramea occidentalis } \\
\text { (L.) A. Rich }\end{array}$ & Bosque primario y secundario & Fruto \\
\hline 4 & $\begin{array}{l}\text { Cócora de bejuco } \\
\text { o solita montañera }\end{array}$ & Strychnos darienensis Seem & Bosque primario & Fruto \\
\hline 5 & Huesito, perlito & Casearia arguta Kunth & Bosque secundario & Fruto \\
\hline 6 & Churima cajeta & Inga goldmanii Pittier & Bosque secundario & Fruto \\
\hline 7 & Juan garrote & Coccoloba excelsa Benth & Bosque primario y secundario & Fruto \\
\hline 8 & Caimito o zapotillo & Pouteria sp. & Bosque primario & Fruto \\
\hline 9 & Chúcharo & $\begin{array}{l}\text { Pouteria cf. multiflora } \\
\text { (A. CD) Eyma }\end{array}$ & Bosque primario & Fruto \\
\hline 10 & Copetona & Ficus insípida Willd & Bosque primario & Fruto \\
\hline 11 & Hobo colorado & Spondias mombin $\mathrm{L}$. & Bosque primario y secundario & Fruto \\
\hline 12 & Hobo & Spondias mombin $\mathrm{L}$. & $\begin{array}{l}\text { Bosque primario y secundario. } \\
\text { Orillas de los caminos }\end{array}$ & Fruto \\
\hline \multirow{2}{*}{13} & \multirow{2}{*}{ Cacaona o bacao } & \multirow{2}{*}{$\begin{array}{l}\text { Theobroma bicolor } \\
\text { Humb. \& Bonpl. }\end{array}$} & \multirow{2}{*}{ Bosque primario y secundario } & Fruto \\
\hline & & & & Semillas \\
\hline 14 & Guacharaco & $\begin{array}{l}\text { Callicarpa acuminara } \\
\text { H. B. K. }\end{array}$ & Bosque primario y secundario & Fruto \\
\hline 15 & Guarumo & Cecropia peltata L. & Bosque primario y secundario & Fruto \\
\hline 16 & Higuerón & Ficus insípida Willd & Bosque primario y secundario & Fruto \\
\hline 17 & Cocorilla guatinaja & Passiflora seemannii Griseb & Bosque secundario & Fruta \\
\hline 18 & Cocorilla de hueso & Passiflora serrato-digitata L. & Bosque secundario & Fruta \\
\hline 19 & Icaco & Chrysobalanus icaco $\mathrm{L}$. & Playa & Fruta \\
\hline 20 & Confite & Bunchosia agentea (Jacq) DC & Bosque primario y secundario & Fruta \\
\hline 21 & Anón de monte & $\begin{array}{l}\text { Rollinia membranácea } \\
\text { Te. \& Pl. }\end{array}$ & Bosque secundario & Fruta \\
\hline 22 & Uvito de playa & Coccoloba uvifera L. Jacq & Playas & Fruta \\
\hline 23 & Churumbelo & $\begin{array}{l}\text { Posoqueria latifolia } \\
\text { (Rudge) R. \& S. }\end{array}$ & $\begin{array}{l}\text { Bosque primario, secundario y en } \\
\text { algunas zonas bajas cerca al mar }\end{array}$ & Fruta \\
\hline 24 & Guanabanito de playa & Annona glabra L. & Zonas boscosas cercanas al mar & Fruta \\
\hline
\end{tabular}




\section{Consumidor}

Parte utilizada

información (1)

\begin{tabular}{|c|c|c|c|c|c|}
\hline Ganado bovino & \multirow{2}{*}{ Barbasco (ictiotóxico) } & \multirow{2}{*}{ Hojas } & & \multirow{2}{*}{$\mathrm{X}$} & \multirow{2}{*}{$\mathrm{X}$} \\
\hline Aves & & & & & \\
\hline \multirow{2}{*}{ Primates } & Infusión para aligerar el parto & Cogollos & & \multirow{2}{*}{$\mathrm{X}$} & \multirow{2}{*}{$\mathrm{X}$} \\
\hline & Baños para bajar fiebre & Ramas & & & \\
\hline Danta (Tapirus bairdii Gill) & Construcción & Vara (tallo) & & $\mathrm{X}$ & $\mathrm{X}$ \\
\hline Primates & $\begin{array}{l}\text { Uso mágico-religioso como } \\
\text { "contra" o protección }\end{array}$ & Raiz & & $\mathrm{X}$ & \\
\hline Aves y humanos & Combustible & Tallo & & $\mathrm{X}$ & $\mathrm{X}$ \\
\hline Fauna (generalización) y humanos & Combustible & Tallo & & $\mathrm{X}$ & $\mathrm{X}$ \\
\hline $\begin{array}{c}\text { Fauna (generalización) } \\
\text { y humanos }\end{array}$ & $\begin{array}{c}\text { Maderable elaboración } \\
\text { de herramientas y combustible }\end{array}$ & Tallo & & $\mathrm{X}$ & \\
\hline Animales de monte (no especifican) & Maderable y combustible & Tallo & & $\mathrm{X}$ & \\
\hline $\begin{array}{c}\text { Neque (Dasyprocta punctata Gray), } \\
\text { la danta y la guagua } \\
\text { (Agouti paca L.) }\end{array}$ & Maderable y combustible & Tallo & $\mathrm{X}$ & $\mathrm{X}$ & \\
\hline Venado & & & $\mathrm{X}$ & $\mathrm{X}$ & \\
\hline $\begin{array}{l}\text { Alimento de fauna del bosque } \\
\text { (no especifican) y humanos }\end{array}$ & $\begin{array}{l}\text { Maderable, cerca viva, } \\
\text { fabricación de artesanías }\end{array}$ & Tallo (todo el árbol) & $\mathrm{X}$ & $\mathrm{X}$ & $\mathrm{X}$ \\
\hline Primates, aves y humanos & Cerca viva & Tallo (todo el árbol) & $\mathrm{X}$ & $\mathrm{X}$ & $\mathrm{X}$ \\
\hline Primates, loros, roedores y ardillas & & & & $\mathrm{Y}$ & $\mathrm{X}$ \\
\hline Humanos & & & & $X$ & $X$ \\
\hline $\begin{array}{c}\text { Alimento de aves, especialmente } \\
\text { la guacharaca (Ortalis cinereiceps } \\
\text { Gray) }\end{array}$ & $\begin{array}{c}\text { Maderable, elaboración } \\
\text { de herramientas y combustible }\end{array}$ & Tallo & & $\mathrm{X}$ & \\
\hline Fauna (generalización). & Maderable, construcción & Tallo & & $\mathrm{X}$ & $\mathrm{X}$ \\
\hline \multirow{2}{*}{ Ganado } & Maderable & Tallo & & \multirow{2}{*}{$\mathrm{X}$} & \multirow{2}{*}{$\mathrm{X}$} \\
\hline & Purgante & Látex & & & \\
\hline $\begin{array}{c}\text { Fauna (generalización) } \\
\text { y humanos }\end{array}$ & $\begin{array}{l}\text { En infusión detiene la } \\
\text { menstruación abundante }\end{array}$ & Flor & $\mathrm{X}$ & $\mathrm{X}$ & $\mathrm{X}$ \\
\hline Humano & & & $\mathrm{X}$ & $\mathrm{X}$ & $\mathrm{X}$ \\
\hline Humano & & & $\mathrm{X}$ & $\mathrm{X}$ & $\mathrm{X}$ \\
\hline Aves y humanos & Combustible & Tallo & $\mathrm{X}$ & $\mathrm{X}$ & $\mathrm{X}$ \\
\hline $\begin{array}{c}\text { Fauna (generalización) } \\
\text { y humanos }\end{array}$ & & & & $\mathrm{X}$ & $\mathrm{X}$ \\
\hline Aves y humanos & Combustibles & Tallo & $\mathrm{X}$ & $\mathrm{X}$ & $\mathrm{X}$ \\
\hline Fauna (generalización) y humanos & Maderable y combustible & Tallo & & $\mathrm{X}$ & X \\
\hline Fauna (generalización) y humanos & & & $\mathrm{X}$ & $\mathrm{X}$ & $\mathrm{X}$ \\
\hline
\end{tabular}




No Nombre común Nombre científico $\quad$ Localización $\quad \begin{gathered}\text { Parte } \\ \text { comestible }\end{gathered}$

$25 \quad$ Nigüito Muntingia calaburata L. $\quad$ Bosque secundario $\quad$ Fruta

$26 \quad$ Guanabanito Annona spraguei Safford $\quad$ Bosque secundario $\quad$ Fruta

Bola de burro,
Cojón de fraile $\quad$ Thevetia ahoual (L.) DC $\quad$ Áreas de sucesión temprana $\quad$ Fruto

\begin{tabular}{ccccc}
\hline 28 & Cresta de gallo o cocaita & $\begin{array}{c}\text { Pentagonia brachyotis } \\
\text { (Standi.) Standi }\end{array}$ & Bosque primario y secundario & Fruto \\
\hline 29 & Baya india & Oxandra xylopioides Diels & Bosque primario & Fruto \\
\hline 30 & Lata montañera & Bactro sigmoidea Burret & $\begin{array}{c}\text { Bosque primario y } \\
\text { secundario avanzado }\end{array}$ & Fruto \\
\hline 32 & Caucauillo & $\begin{array}{c}\text { Herrania purpurea } \\
\text { (Pittier) R. E. Schult }\end{array}$ & Bosque primario y secundario & Fruto \\
\hline
\end{tabular}

Bosque secundario y áreas en sucesión
Fruto

\begin{tabular}{|c|c|c|c|c|}
\hline 34 & Topotoropo & Physalis angulata $\mathrm{L}$. & Áreas en sucesión y potreros & Fruto \\
\hline 35 & $\begin{array}{c}\text { Bejuco de San Juan } \\
\text { de Uva }\end{array}$ & $\begin{array}{l}\text { Vitis tiliaeafolia } \\
\text { J. \& B. ex Boem. }\end{array}$ & Bosque secundario & Fruto \\
\hline 36 & Membrillo & Grias cauliflora $\mathrm{L}$. & Bosque primario y secundario & Fruto \\
\hline 37 & $\begin{array}{l}\text { Marañón Fruta } \\
\text { por fuera }\end{array}$ & $\begin{array}{l}\text { Anacardium } \\
\text { occidentale } \mathrm{L} \text {. }\end{array}$ & $\begin{array}{l}\text { Bosques secundarios, áreas } \\
\text { en sucesión y potreros }\end{array}$ & $\begin{array}{c}\text { Fruto } \\
\text { Semilla }\end{array}$ \\
\hline 38 & Almirajó & Patinoa almirajo Cuatrec. & Bosques secundarios & Fruto \\
\hline 39 & Carne de pobre & $\begin{array}{l}\text { Gustavia superba } \\
\text { Kunth Berg }\end{array}$ & $\begin{array}{c}\text { Bosques primarios } \\
\text { y secundarios }\end{array}$ & Fruto \\
\hline 40 & Corozo & $\begin{array}{c}\text { Orbignya cuatrecasana } \\
\text { Dugand }\end{array}$ & $\begin{array}{c}\text { Bosques primarios y secundarios, } \\
\text { zonas cercanas a las huertas }\end{array}$ & Fruto \\
\hline
\end{tabular}

Notas: (1) 1. afrodescendientes; 2. chilapos; 3. interior del país. (2) Los interlocutores han establecido que sólo es posible la ingesta en humanos cuando el fruto está completamente maduro. Sharma, Dawra y Makkar [continua] 
Consumidor

Otros usos

Parte utilizada

Fuente de información (1)

\begin{tabular}{|c|c|c|c|c|c|}
\hline \multirow[t]{2}{*}{ Aves y humanos } & $\begin{array}{l}\text { Fabricación de majagua (cuerda } \\
\text { para unir listones de madera) }\end{array}$ & $\begin{array}{l}\text { Corteza de árboles } \\
\text { jóvenes }\end{array}$ & \multirow[t]{2}{*}{$\mathrm{X}$} & \multirow[t]{2}{*}{$\mathrm{X}$} & \multirow[t]{2}{*}{$\mathrm{X}$} \\
\hline & Combustible y maderable & Tallo & & & \\
\hline \multirow{2}{*}{$\begin{array}{c}\text { Fauna (generalización } \\
\text { y humanos) }\end{array}$} & Baños relajantes & Hoja & \multirow{2}{*}{$x$} & \multirow{2}{*}{$\mathrm{x}$} & $\mathrm{y}$ \\
\hline & Fabricación de majagua & Corteza de árboles jóvenes & & & \\
\hline
\end{tabular}

Uso mágico-religioso para contrarrestar la magia de terceros

Fauna (generalización) $\mathrm{y}$ humanos

Medicinal, para aliviar el pujo de los niños, provocado por un adulto sofocado o "mal dormido"

Corteza

Fruto

(

Fauna (generalización) y humanos

$$
\text { Combustible }
$$

Tallo

X

Alimento para animales (no especi-

fica) y para el consumo humano.

Maderable, fabricación de herramientas, combustible

Vara (los tallos) $\quad \mathrm{X} \quad \mathrm{X}$

Fauna (generalización)

y humanos

\begin{tabular}{ccl} 
Maderable & Tallo & X \\
\cline { 1 - 2 } Las semillas & Tostadas
\end{tabular}

Fauna (generalización) y humanos

Fauna (generalización) y humanos

Maderables para la construcción

Tallo

X

Se obtiene majagua del interior

Corteza

Fauna (generalización) $\mathrm{y}$ humanos

Se obtiene de las hojas una baba que se aplica sobre el cuero cabelludo para refrescar

Hoja X X

Evita la caída del cabello

Fruto

Fauna (generalización) y humanos

X X

Fauna (generalización) y humanos X

Fauna (generalización) y humanos X

Fauna (generalización)

Humanos: se tuesta

En infusión controla la presión arterial y los niveles de glucosa en sangre

Fauna (generalización) y humanos,

ha sido cultivada

X X
Fauna (generalización) y humanos

El arilo de las semillas se machaca y adiciona en preparación de sopas y arroz

$$
\text { Usado como leña }
$$

Extracción de aceite
Semillas X X

Roedores, ardillas, guaguas y humanos

(1987), identificaron su alta toxicidad por la presencia de lantadenos A y B identificados en las hojas, por lo que su uso es de alto riesgo. (3) L., abreviatura genérica usada en especies determinadas por Carl Linneo. 


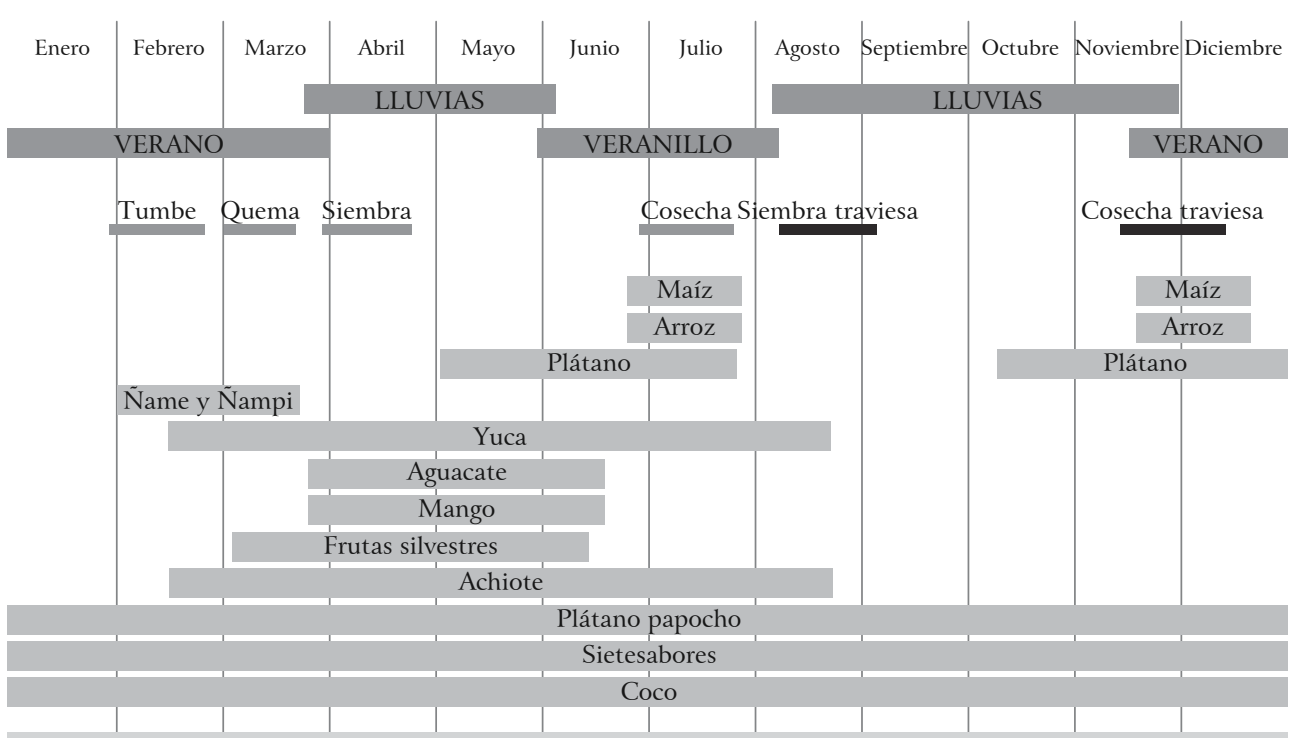

Figura 1 - Calendario agrícola en San Francisco de Asís. Se ilustra la producción de alimentos en el corregimiento de acuerdo con la temporada de lluvias y periodo seco. La época de mayor fructificación y de cosecha de cultivos de subsistencia ocurre entre los meses de febrero y junio. Fonte: Elaborado a partir de los registros de campo durante el año 2011.

Quienes hicieron esta asociación fueron los primeros pobladores del corregimiento llegados en la década del 60 procedentes del Urabá Antiqueño, de los departamentos de Córdoba, Bolívar y del interior del país. Los migrantes establecieron una estrecha relación con las dinámicas del bosque en la extracción de recursos naturales para su supervivencia. Muchos de ellos fueron aserradores vinculados a la fabricación de botes de madera y/o cazadores, por lo tanto, usaban como complemento nutricional las frutas silvestres en las largas jornadas de permanencia en el bosque.

"Nosotros cuando íbamos a tumbar monte comíamos mucha fruta para calmar el hambre, comíamos de lo que los animales comían; como yo estaba recién llegado, entonces uno todavía no sabía bien cuáles se podían comer, ya luego con el tiempo una va aprendiendo" [IS, octubre de 2011].

A su vez, el consumo de frutos silvestres estuvo vinculado a la población infantil de San Francisco como resultado de los procesos de socialización en el medio natural, cultural y familiar.

"Yo recuerdo que éramos muchos amiguitos, hordas de niños nos íbamos para el bosque o a la playa a comer nigüito, velita, churumbelo y confite; ese sí que era especial. Nosotros sabíamos por dónde estaban porque el papá 
de alguno decía donde había una u otra fruta. Nos llenábamos por allá y bajábamos tarde y llenos. Ahora, ya eso se ha perdido, ya ahora los pelaos no van, escasamente van a la playa a comer uvito y ya. Estos pelaos no van al monte, seguro por miedo a la culebra, además ya no hay mucho de esas matas y hay que adentrarse mucho para conseguir las frutas que uno tenía antes a la mano" [ER, agosto de 2011 ].

El consumo de frutas silvestres fue considerado por la población como un complemento nutricional, mas no como una necesidad en la ingesta calórica. Por su ubicación en la franja del litoral Caribe, la comunidad estuvo vinculada a la pesca y a una suficiente producción de arroz, yuca, ñame y plátanos, productos básicos de la dieta costeña. En la actualidad, la producción agrícola local y la pesca se han reducido significativamente y han aumentado los productos alimentarios de origen industrial, en especial las golosinas, fenómeno que provoca que el consumo de frutas locales originarias del bosque y el conocimiento de las mismas estén en declive en la región.

Algunas especies frutales silvestres tienen usos alternativos en medicina, sirven de materia prima para la fabricación de herramientas y utensilios, pero son principalmente especies maderables, por lo que se ha ejercido mayor presión sobre ellas. En la tabla 1, se incluyen estas especies en tanto su clasificación taxonómica, localización, características más recurrentes según nuestros interlocutores, tipo de animales que las consumen y otros usos relacionados.

Todas las frutas identificadas en el área de estudio fueron reconocidas por al menos un interlocutor chilapo. Mientras tanto, 19 especies fueron reconocidas por al menos un interlocutor afrodescendiente, y 26 especies fueron identificadas por al menos un interlocutor paisa. A partir de estas diferencias en el número de especies reconocidas de origen silvestre, es posible inferir que los conocimientos están relacionados con la vinculación de las poblaciones con la selva. La población chilapa ha sido históricamente asociada a los procesos de apertura del bosque en el Urabá antioqueño, chocoano y en las llanuras del Sinú para la ampliación de la frontera agrícola, de ahí sus conocimientos de las especies maderables y las no maderables (Ruiz-Serna 2006). En San Francisco, los hijos de colonos chilapos hoy continúan aserrando y comercializando la madera en la localidad y fuera de ella.

Los afrodescendientes también han intervenido en el bosque pero no en las proporciones anteriormente descritas. Previo a la introducción de las embarcaciones de fibra de vidrio y acrílico a mediados de la década de los 80, esta población comercializó canoas fabricadas en madera de caracolí (Anacardium excelsum (Kunth) Skeels) con indígenas Kuna de las islas de San Blas (Panamá), comercio que se estableció por casi 15 años. Esto redujo significativamente la población de caracolíes en el sector y por lo tanto la fabricación de estas embarcaciones artesanales. 
Desde su asentamiento en la década de los 60, el bosque fue fuente de proteína animal, de plantas medicinales y de materias primas para los afrodescendientes, sin desconocer que la ubicación de esta población en cercanías del mar la inscribe en dinámicas asociadas al litoral. Por ejemplo, la dieta del afro se basa en tubérculos, arroz cultivado en parcelas, y al pescado de mar, por lo tanto, el acceso a las frutas silvestres es menor, a no ser que estas crezcan cerca a la residencia o a la playa como el uvito de playa, el icaco y el guanabanito de playa, las cuales son muy valoradas por la población negra.

Estas especies en particular son plenamente identificadas por los niños de San Francisco y consumidas durante su temporada de fructificación, pero la pérdida de ejemplares de estas frutas, producto de la erosión causada por la explotación de arena utilizada para la construcción de viviendas es cada vez mayor. Específicamente para el caso del uvito de playa, presionado además por servir como combustible para fogones de leña.

Los grupos humanos que se han asentado en el corregimiento desde principios de los 70, principalmente paisas, han logrado identificar, conocer e incorporar estas especies gracias a su ubicación en las zonas rurales y boscosas del corregimiento que han consolidado como áreas de reserva ecológica de la sociedad civil, lo que les permite un vínculo directo con el ambiente natural, el reconocimiento de especies silvestres comestibles, sus diversos usos, entre otros beneficios. ${ }^{7}$ Esta interacción ha sido parte de un proceso de socialización y convivencia con afrodescendientes y chilapos que les ha permitido participar en la construcción de un conocimiento común en el cruce multicultural.

Algunas de las prácticas fomentadas por este grupo, en conjunto con afros y chilapos, se han basado en el desarrollo de estrategias locales para la conservación del ambiente. Se han puesto en marcha actividades de educación ambiental y de reforestación para contrarrestar los efectos de las prácticas insostenibles. Sin embargo, en el marco de la consolidación de estos procesos se realizaron programas financiados por la Presidencia de la República y cooperación internacional, que causaron profundas trasformaciones a nivel social

7 "La red de reservas tiene un papel muy importante para la conservación puesto que: (I) son centros de promoción a nivel local y subregional de la participación de la sociedad civil en conservación y uso sostenible de la biodiversidad y, en consecuencia, son facilitadores en el establecimiento de sinergias con el sector público encargado de llevar a cabo acciones de conservación. (2) Pueden facilitar el establecimiento de zonas de amortiguación y corredores biológicos y otras conexiones entre fragmentos y/o áreas protegidas. (3) En algunos casos pueden ser la única posibilidad para la conservación de una localidad importante en zonas donde sea difícil establecer áreas protegidas de carácter público" (Hurtado et al. 2008: 236). Estos escenarios de conservación se definen como territorios o porciones de territorios en los cuales diversos actores coinciden en su apreciación de la necesidad de desarrollar acciones conjuntas para mantener, a largo plazo, determinados atributos biofísicos o procesos ecológicos de importancia por razones estéticas, culturales, funcionales o de aprovechamiento directo. 
y económico. ${ }^{8}$ Por ejemplo, el programa Familias Guardabosques otorgó a sus socios, que eran dueños de reservas y parcelas, incentivos económicos durante cuatro años, lo que redujo el desarrollo de actividades productivas locales. $\mathrm{Al}$ subsidiar las familias con ingresos bimensuales, sus necesidades básicas quedaban cubiertas eximiéndolas del cultivo de sus parcelas y de las actividades de autosubsistencia; este programa está actualmente inactivo. Adicionalmente, los conflictos por la tierra y el fenómeno del narcotráfico, el "dinero fácil", han hecho que los procesos comunitarios estén cada vez menos orientados a la conservación, a pesar de los esfuerzos que algunos interioranos y organizaciones desarrollan aún en aras de la protección de los recursos naturales (Álvarez-Salas y Gálvez-Abadía 2014).

Los pocos agricultores de la región reportan que un indicador adicional de la pérdida de especies silvestres en los bosques del Darién es la llegada de animales a los cultivos de pancoger. Si bien la presencia en áreas urbanas de monos cariblancos (Cebus capucinus L.), ardillas (Sciurillus pusillus Geoffrey y Syntheosciurus brochus Bangs), ratas de monte (Oryzomys talamancae Allen) y pájaros diversos fueron una constante, no lo ha sido su incidencia en cultivos de arroz y maíz que hoy se presenta con frecuencia, producto del deterioro continuado de sus hábitats. Un interlocutor local explica este fenómeno:

"Acá hay un problema y es grave con los animales. Ya los micos están comiendo maíz que nunca aquí comían maíz y la gente de todas maneras le gusta sembrar la mata de maíz y ellos solo esperan que la matica crezca, espigue y eche la mazorquita porque ahí mismo ellos [los micos] son los que la cogen, entonces ellos comen maíz y no alcanza pa' dejarle al dueño sino que todo lo recogen. El dueño dice: bueno, estoy trabajando pues pa' los micos, pero, yo tengo que tener estrategia pa' ver cómo lo extermino, el mico uno no lo puede alejar porque él no se va. Es doloroso porque hay gente que utilizan veneno y matan cuarenta, cincuenta y no ¿pa' qué los matan? También a uno no le gusta que los maten, mejor no siembren nada o no sé, porque ese poco de animalitos matarlos y ver treinta, cuarenta animalitos de esos no aguanta. Además, que ellos son muy graciositos, haga de cuenta un niño, por eso da tanto pesar" [E-M, julio de 2011].

En la columna 6 de la tabla 1 , las frutas silvestres se asocian con el consumo de especies animales y en algunos casos, los habitantes de la región conocen la especie específica que las consume. La llegada del cariblanco, la ardilla y el

8 Los programas de Familias Guardabosques y Proyectos Productivos son dos iniciativas que se desarrollaron entre 2003 y 2009, con la participación de la Oficina de Naciones Unidas contra la Droga y el Delito (UNODC), en conjunto con la Dirección de Programas contra Cultivos Ilícitos (DPCI). Este programa se desarrolló en el marco Plan Colombia (UN/PRC 2007). 
ratón de monte se han convertido en las "plagas" más recurrentes en las pocas parcelas agrícolas que aún existen en San Francisco. A pesar de que algunos interlocutores sostienen que es "necesario cultivar para el mico, los pajaritos y para la familia porque todos tienen derecho a comer" [JV, noviembre de 2011], en términos generales, esta situación ha desestimulado la producción agrícola local haciendo a esta población más dependiente del mercado externo.

\section{Frutas fomentadas e introducidas para el consumo humano}

Los frutos del bosque fueron tan importantes como las especies fomentadas e introducidas por la población que poco a poco se asentó en la localidad. Las frutas no sólo marcaron temporadas durante el año agrícola basadas en la fructificación de especies:

"aquí se conoce que la temporada del mango y el aguacate es como entre mayo y julio y la traviesa en septiembre, aunque ese mes también le decimos por acá septihambre porque no hay nada que cosechar. Así funciona para casi todas las cosechas" [JP, noviembre de 2011].

Las frutas fomentadas también definieron los procesos de ocupación y uso de tierras baldías, como se verá seguidamente.

De acuerdo con nuestros interlocutores, el proceso de ocupación en San Francisco de Asís lo define el origen de los nuevos ocupantes y el proyecto de vida que desean desarrollar en la región. Por ejemplo, para el chilapo sus estrategias económicas están orientadas hacia la explotación de madera, pero al localizarse en una zona clave para la conservación biológica, ${ }^{9}$ su práctica se torna ilegal. ${ }^{10}$ Luego de talado el bosque, se comercializan las maderas de interés económico, mientras que se queman los arbustos y las herbáceas. Posteriormente se realizan dos siembras de maíz o arroz para luego establecer los cultivos de autoabastecimiento como yuca y ñame o los pastos para el ganado. Los locales denominan a este proceso "amansar la selva" o "poner bonito",

9 Cf. WWF Colombia, Plan de Acción del Complejo Ecorregional Chocó Darién, Cali, Unión Europea, Ministerio Británico para el Desarrollo Internacional y WWF Suecia y Reino Unido, p. 8 (cit. en Gálvez 2009: 3).

10 "El Ministerio de Ambiente y Desarrollo Sostenible conjuntamente con organismos nacionales adscritos y vinculados con el ministerio, establecen los lineamientos para otorgar concesiones, permisos, autorizaciones y licencias ambientales por ley para el uso, aprovechamiento y movilización de los recursos renovables o para el desarrollo de actividades que puedan afectar el medio ambiente". Los permisos están definidos en la Resolución 0260 de 2011 . A su vez, la Resolución 3184 de 27 de septiembre de 2010 establece las directrices de la Corporación Autónoma Regional para el desarrollo del Chocó - Codechocó -, para el manejo y control de recursos biológicos en la zona. Si bien, la corporación no concedió permisos a aserradores locales para explotación de maderables en la región, tampoco ejerce control sobre los evidentes procesos de tala indiscriminada en los bosques de San Francisco de Asís. 
actividad que hace de la parcela una unidad significativamente más costosa que un lote de bosque, por la inversión de mano de obra para su domesticación.

Por otra parte, para los pobladores que llegaron del interior del país se observaron diferentes formas de apropiación: algunos establecieron ganaderías con la estrategia anteriormente descrita; otros mantuvieron sitios para la conservación y protección de los recursos, y finalmente, una colectividad de aproximadamente 25 núcleos familiares se estabilizaron para desarrollar procesos de conservación vinculada a la silvicultura. En ésta, el primer elemento de transformación y de apropiación del terreno fue el cultivo de las especies frutales.

"Yo llegué a San Francisco con seis niños y la esposa. Lo primero que yo hice, y porque me lo enseñaron, fue sembrar frutales por toda la tierrita. Yo conseguía las semillas del bosque, del pueblo, de otras fincas y la gente me regalaba. Yo pensé, en seis años tengo frutas y eso es comida; yo me proyecté al futuro para garantizar otras fuentes de alimentos. También sembré, pero lo primero que se hace en San Pacho es sembrar frutales" [NL, enero de $2011]$.

Los árboles frutales garantizan la posesión de la tierra, demarcan territorio y son una garantía de permanencia futura en la región para los llegados del interior.

En este sentido, el cultivo de árboles frutales es considerado como una "mejora" a la unidad productiva. Cuando la tierra era tomada en arriendo y se instalaban frutales con un ciclo reproductivo largo, que implicara tener cosechas por años por el carácter permanente de estas especies, las mejoras requerían ser pagadas por el dueño al inquilino con dinero o con tierra. Esta fue una de las estrategias usadas entre los nuevos colonos para adquirir una finca, pues las mejoras superaban muchas veces, el valor comercial que para la época tenía la tierra.

En la tabla 2 se ilustran 20 especies frutales fomentadas e introducidas en la región; la mayoría de ellas llegadas en los procesos de colonización y asentamiento desde el Urabá y la zona andina del departamento de Antioquia y de los departamentos de Córdoba y Bolívar. Los conocimientos sobre la implementación de los cultivos y las estrategias de cuidado se dan en la práctica agrícola local y son difundidos de forma oral. Pero también se han trasformado y perfeccionado, gracias al saber experto que llega a la región con los eventuales programas sociales y de manera informal a través del intercambio con el turista.

La época de fructificación y cosechas de estas variedades ocurre también en el primer semestre del año, entre los meses de febrero y mayo. Esta temporada coincide con la Semana Santa, tradición ya perdida entre los habitantes 


\section{Tabla 2}

\section{Especies cultivadas y fomentadas en el corregimiento de San Francisco de Asís}

\begin{tabular}{|c|c|c|c|c|}
\hline No. & Nombre común & Nombre científico & Localización & Parte usada \\
\hline \multirow{3}{*}{1} & \multirow{3}{*}{ Coco } & \multirow{3}{*}{ Cocos nucifera $\mathrm{L}$. } & \multirow{3}{*}{ La playa y cultivado } & Fruto \\
\hline & & & & Tallo \\
\hline & & & & Casco del fruto \\
\hline \multirow{2}{*}{2} & \multirow{2}{*}{ Chontaduro } & \multirow{2}{*}{ Bactris gasipae Kunth } & \multirow{2}{*}{ Cultivado y silvestre } & Tallo joven \\
\hline & & & & Tallo \\
\hline 3 & Mango & Mangifera indica L. & Cultivado & Tallo \\
\hline 4 & Guanábana & Annona muricata L. & Cultivada & \\
\hline 5 & Piña & Ananas comosus (L.) Merr. & Cultivada & \\
\hline 6 & Papaya & Carica papaya $\mathrm{L}$. & Cultivada & \\
\hline
\end{tabular}

7 Sietesabores Diospyros blancoi A. DC Cultivado

8 Aguacate Persea americana Mill Cultivado Hoja

\section{Fruto}

10 Cacao Theobroma cacao L. Cultivado Semilla

\begin{tabular}{|c|c|c|c|c|}
\hline 11 & Arazá & $\begin{array}{l}\text { Eugenia stipitata } \\
\text { Mc Vaugh. }\end{array}$ & $\begin{array}{l}\text { Cultivado. } \\
\text { Crece en orillas de caminos. }\end{array}$ & \\
\hline 12 & Guayaba & Psidium guajaba L. & $\begin{array}{l}\text { Cultivada. Se encuentra en bosques } \\
\text { en sucesión y en potreros. }\end{array}$ & Cogollo y fruto \\
\hline 13 & Níspero & $\begin{array}{l}\text { Manilkara huberi } \\
\text { (Ducke) A. Chev. }\end{array}$ & $\begin{array}{l}\text { Cultivado. Se encuentra } \\
\text { en bosques en sucesión. }\end{array}$ & Tallo \\
\hline 14 & Borojó & $\begin{array}{l}\text { Borojoa patinoi } \\
\text { Cuatrec. }\end{array}$ & $\begin{array}{l}\text { Cultivado. Se encuentra en bosques } \\
\text { en sucesión y potreros. }\end{array}$ & \\
\hline 15 & Guayabo & $\begin{array}{l}\text { Gonzalagunia panamensis } \\
\text { (Cav.) K. Schum. }\end{array}$ & $\begin{array}{l}\text { Cultivado. Se encuentra en bosques } \\
\text { en sucesión y potreros. }\end{array}$ & Tallo \\
\hline
\end{tabular}

Fue monocultivo.

16 Noni Morinda citrifolia L. Hoy está presente en forma aislada Hoja
en huertas y potreros. 


\section{Generalidades}

\section{Otros usos conocidos}

Producción de aceites

Base de la culinaria local caribeña en la preparación de arroz, pescados y dulces.

\begin{tabular}{c} 
Producción de aceites \\
\hline Construcción \\
Sahumerio
\end{tabular}

Consumo del palmito

La harina con alto valor nutricional y afrodisíaca.
Fruto de origen asiático e introducido al continente durante la conquista y en San Francisco fue sembrado en forma extensiva en la década de los 60 .

\section{Madera de baja calidad para la construcción}

Planta fomentada en la región y usada en preparaciones.

Planta endémica recientemente fomentada entre algunos agricultores.

Fruto consumido en un estado previo a su maduración o "biche" en forma de bastimento.

Planta originaria de Filipinas. Su semilla fue introducida a la región en 1977 por una familia procedente del Urabá Antioqueño. Recibe su nombre por tener matices de múltiples frutas.

Planta que marca el inicio de la temporada agrícola. Tiene uso medicinal ente la población afrodescendiente.
Para apresurar el parto: se toman una y media hojas en infusión y se da a tomar durante el trabajo de parto.

Extracción de aceite

Semilla introducida en Acandí y Unguía por una empresa privada para el desarrollo de sistemas productivos orgánicos. Hoy solo se reproduce en forma extensiva en Unguía. Su declive fue generado por convertirse en alimento de fauna local.

La semilla de origen amazónico fue introducida por un habitante de la región en el año de 1993. Desde entonces se usa en la preparación de mermeladas por su capacidad aglutinante.

Especie endémica con propiedades medicinales. Consumo directo y trasformada en mermeladas.
Daños estomacales en infusión: el fruto verde, más coco tierno y un limón. Se agregan tres cogollos.

Por su uso maderable tiene gran demanda local, el número de individuos en el área se ha reducido drásticamente así como el consumo de su fruta

Maderable

Es un fruto apreciado entre la población. Hoy en día es la materia prima

principal en la preparación de mermeladas.

Planta conocida y aprovechada por los afrodescendientes e interioranos. Se usa en mermeladas y dulces.

Para fabricar cabos de herramienta

La región fue una de los mayores productoras en la década de los 90 cuando se convirtió en un milagro económico, al atribuirle propiedades medicinales. Hoy es nula su comercialización, pero se usa como trata- 


\begin{tabular}{|c|c|c|c|c|}
\hline No. & Nombre común & Nombre científico & Localización & Parte usada \\
\hline 17 & Limón mandarino & Citrus $\times$ limonia & Cultivado & Fruto \\
\hline \multirow[t]{2}{*}{18} & \multirow[t]{2}{*}{ Jagua } & \multirow[t]{2}{*}{ Genipa americana $\mathrm{L}$. } & \multirow[t]{2}{*}{$\begin{array}{l}\text { Árbol localizado en las huertas, } \\
\text { potreros y cerca de las casas. }\end{array}$} & Fruto inmadur \\
\hline & & & & Tallo \\
\hline 19 & Zapote de indio & $\begin{array}{l}\text { Manilkara zapota } \\
\text { (L.) P. Royen. }\end{array}$ & \multicolumn{2}{|l|}{ Cultivada } \\
\hline 20 & Lulo chocoano & Solanum topiro Dunal & Fomentada en huertas y solares. & Fruto inmadur \\
\hline \multicolumn{5}{|c|}{$\begin{array}{l}\text { negros y chilapos de San Pacho, pero vigente en algunos municipios de Bolív } \\
\text { Atlántico y Córdoba. Gracias a la oferta frutícola, durante la celebración de } \\
\text { Semana Santa, las familias fabricaban dulces artesanales que eran objeto } \\
\text { intercambio. }\end{array}$} \\
\hline \multicolumn{5}{|c|}{$\begin{array}{l}\text { "En la época de Semana Santa era una tradición aquí. Todos en las casas } \\
\text { cíamos dulces de las frutas que estaban en cosecha, por ejemplo de: ñame, } \\
\text { yuca, de mango, de níspero, de borojó, de guayaba, de zapote, bueno, } \\
\text { todo lo que había en cosecha. Pero los más tradicionales eran de yuca y } \\
\text { me, su sabor era como el arequipe. La preparación era en fogón de leña y } \\
\text { hacían desde el lunes hasta el miércoles más o menos, porque el jueves y } \\
\text { ernes no se podía trabajar. También se preparaba lo que es el bastimento }{ }^{11} \\
\text { solo quedaba ir por la liga fresca. }{ }^{12} \text { Esto era una fiesta de Semana Santa } \\
\text { lamente" [JV, septiembre de } 2011] \text {. }\end{array}$} \\
\hline
\end{tabular}

Según los habitantes, era una oportunidad intercambiar dulces como regalos con la finalidad de fortalecer lazos de parentesco y de amistad. Para algunos, la pérdida de esta costumbre culinaria está relacionada con la llegada de la iglesia evangélica que considera el contexto religioso de la Semana Santa como una tradición propia de la tradición romano-católica. Dice el líder evangélico:

"La Semana Santa nosotros la celebramos diferente y reconocemos su importancia. Nosotros los evangélicos, creemos que la Semana Santa católica es una celebración de idolatría. Por eso, nosotros recordamos el sacrificio del

11 En la cocina chilapa y afrodescendiente, se denomina "bastimento" a las porciones cocidas de yuca, arroz, plátano y ñame que acompañan la comidas.

12 "Liga" se refiere a la porción de proteína incluida en la alimentación: pescado, carnes y huevo. 
Hace parte importante de la tradición indígena Embera y Kuna. El fruto maduro, el cual tiene propiedades diuréticas, estomacales y revulsivas. Está indicado contra la enteritis crónica y la hidropesía.
La tinta extraída de fruta inmadura es usada como antisolar, previene manchas solares y como repelente. Tiene propiedades enteógenas.

Es maderable.

Fruta caribeña consumida en jugos, dulces y vinos artesanales.

hijo de Dios Nuestro Señor pero no de esa forma, y eso le hemos inculcado a nuestros feligreses; cambiar todo acto que ofenda a Dios" [Pastor, agosto de 2011$]$.

Como práctica cultural afro y chilapa, la tradición dulcera desapareció con el cambio de filiaciones religiosas y con la apertura de la población a un mercado avasallante en términos alimentarios y a una economía cada vez más monetizada. Hoy en día la circulación de preparaciones a base de frutas locales está en manos de paisas interioranos, que promueven la venta de productos como una tendencia alimentaria tropical para turistas.

"Yo traigo las frutas del borojó de la finca que tenga producción. Con ellas hago la mermelada que es muy fácil porque es cocinar a fuego lento la pulpa con bastante panela por dos horitas, hasta reducirla. Yo ya tengo los envases y tengo las etiquetas con la marca que las mando hacer a Medellín; se envasan, se cierran y se adorna el frasco con concha de coco. Se deja reposar y los vendo en la tienda a \$5000 [US\$ 2,6]. Y así hago con las frutas que estén en cosecha” [JV, octubre de 2011 ]

Al mismo tiempo, un poblador ha logrado desarrollar productos alimentarios y cosméticos como vinos, mermeladas y aceites, que son vendidos a los turistas en las tiendas locales. Salazar Zapata (2012) reseña en su diario de campo de 2008, el proceso experimental en la creación de vinos locales y cómo el jengibre (Zingiber officinale Roscoe) se convirtió en uno de los ingredientes más importantes en esta preparación:

“J. aprendió de E. que murió en diciembre pasado a los 80 años de edad. Él le enseñó una técnica básica que ha ido depurando a través de un lento 
proceso de experimentación: ha ido perfeccionando las fórmulas, los procedimientos, y en general los métodos para incrementar paulatinamente la producción. Ha recibido asesoría técnica en la U. de A. para mejorar el producto. Con el vino de jengibre, el primero con el que experimentaron, ha llegado a un punto más acorde con el gusto de los clientes: antes era muy picante y seco, ahora es un poco más dulce y bajó la intensidad del pique. Había leído en alguna parte que es posible hacer vino de casi cualquier planta: tubérculos, flores, frutas; como el jengibre es tan común en San Pacho hicieron la prueba, él y E., empezaron a catar su sabor y a dárselo a probar a los amigos [...]. De voz a voz se ha ido defendiendo el vino de J. en el mercado ya que a simple vista, factores como la cristalinidad o el empaque plástico con tapa rosca reciclado, no lo hacen un producto muy atractivo al cliente" (Gálvez 2009: 10, en Salazar Zapata 2012, subrayado de la autora).

A partir de esta experiencia, se fomentó la producción de vinos artesanales de jengibre (Zingiber officinale) para satisfacer la demanda local de licores. Esta planta, condimento originario de la India y China e introducida a la región por agricultores de origen antioqueño, es cultivada exitosamente y ostenta propiedades medicinales como: cicatrizante, inmunomodulador y antigripal (Mascolo et al. 1989), características muy valoradas entre los habitantes de la región por la alta incidencia de enfermedades respiratorias, cutáneas y parasitarias.

Por otra parte, el coco es un ingrediente esencial en San Pacho, y en general de la cocina caribeña. Chilapos y afrodescendientes comparten preparaciones de arroz y pescados en fricasé a base de condimentos, en los que el elemento fundamental es la leche de coco extraída manualmente. Gálvez (2009: 8) define a Cocos nucifera como un fondo de cocina que marca la identidad culinaria local, fomentada tanto en hoteles y en modestos restaurantes ubicados a la orilla del mar como en los hogares. El coco es además la base de postres, galletas y mermeladas artesanales.

"Yo preparo todos los días el arroz de coco, ya sea clavado [adición de queso costeño], el normal o arroz negrito. Ese es el que más le gusta a los niños, porque tú haces el caramelo con una taza de leche de coco y azúcar y lo dejas reducir hasta que se hace el caramelo junto con el aceitico del coco, luego adicionas más leche, el arroz, su sal y se termina de secar. Siempre hago una olla y no dura sino para una comida. Y cuando se hacía con el arroz subido de aquí era todavía más especial; ya lo hago con arroz de la tienda pero queda también muy gustoso" [AM, septiembre de 2011]. ${ }^{13}$ 
Junto con el coco, el sietesabores (Diospyros blancoi) se configura como especie de gran valor. Esta fue introducida desde Filipinas (Lizana 1990), donde hoy está en peligro de extinción por su uso maderable y es conocida como "hierro de madera" (Pobar 2003). También se vincula a usos tradicionales, por ejemplo la fruta verde es usada para la cicatrización de heridas, el aceite de las semillas es extraído para detener la diarrea y la disentería, la infusión de frutas en gargarismos como parte del tratamiento de la estomatitis aftosa (Bensky, Clavey y Stoger 2004). En Bangladesh, el jugo de la corteza se utiliza en el tratamiento contra las mordeduras de serpientes, los resfriados, en problemas cardíacos, de hipertensión, en las mordeduras de araña, en los dolores de estómago, la diabetes, los eczemas (Ghani 1998) y se ha evidenciado la acción antioxidante de las hojas (Lee et al. 2006; Ragasa et al. 2009). También es valorado por sus características nutricionales, como una fuente ideal de calcio, vitamina $\mathrm{B}$, hierro, proteínas y compuestos fenólicos que proporcionan antioxidantes de gran alcance (Pobar 2003).

Para la comunidad analizada y en especial para los paisas es muy valorada como alimento, sin embargo es poco apetecida entre los afrodescendientes y chilapos.

"Esta es una fruta súper linda, ella sabe a de todo y sabe a ella misma al mismo tiempo. Sabe a manzana, a pera, a banano, a guayaba, a guanábana, como a guama y mango. Por eso se llama así porque tiene siete sabores, yo creería que más. Tal vez todos esos sabores hacen un sabor especial y único. Lo más lindo es que usted se toma el jugo o se la come así, y queda llenísimo, yo creo que eso, debe ser muy nutritiva" [RL, noviembre de 2011].

Nuestros interlocutores indican que su introducción a la región ocurrió gracias a una familia proveniente de la vertiente oriental del golfo de Urabá. Inicialmente fueron sembradas cuatro semillas en la finca que habían adquirido cerca a la playa, de las cuales germinaron dos hasta convertirse en árboles maduros. Después de seis años ocurrió la primera floración, la cual fructificó luego de cuatro meses. Con las semillas producto de esta cosecha, fue posible su dispersión a otros sectores del corregimiento.

Para el turista, es un fruto que constituye un enigma gustativo generado por el nombre, el cual invita a su descubrimiento: "Yo oí de ese fruto inmediatamente llegué aquí; me dijo la dueña del hotel: no se vaya sin probarlo, es delicioso, es una cosa que no se sabe a qué sabe" [turista, diciembre de 2011]. La invitación surge de los locales para compartir sus productos con los visitantes.

cultivado en San Francisco en forma recurrente hasta mediados de los 90. En la actualidad no es viable su producción por la carencia de mano de obra y de tierras para su labranza. Para ampliar, ver ÁlvarezSalas (2014). 
Por su llamativo nombre y el interés que genera entre los turistas es recurrente la pregunta: ¿a qué sabe el sietesabores? Para dar respuesta a este cuestionamiento se practicó, por solicitud de nuestros interlocutores, un análisis sensorial el cual es una herramienta subjetiva que permite la identificación de sabores y texturas en los alimentos a partir de un panel de expertos.

El análisis sensorial definió los descriptores del sabor basados en una frecuencia de aparición entre los jurados identificados en la tabla 3.

A partir de esto, 16 jurados definieron el perfil de sabor (figura 2), donde el valor más bajo es 1 y el más alto es 5 , a partir de sensaciones somato-sensoriales residuales y/o persistentes en la muestra.
Tabla 3

Descriptores de sabor sietesabores (Diospyros blancoi)

\begin{tabular}{cc} 
Descriptor del sabor & Frecuencia \\
\hline Dulce & 16 \\
Amargo & 13 \\
Frutal & 16 \\
Acido & 15 \\
Guanábana & 14 \\
Guayaba & 15 \\
Floral & 16 \\
Zapote & 16 \\
Verde & 10 \\
Papaya & 16
\end{tabular}

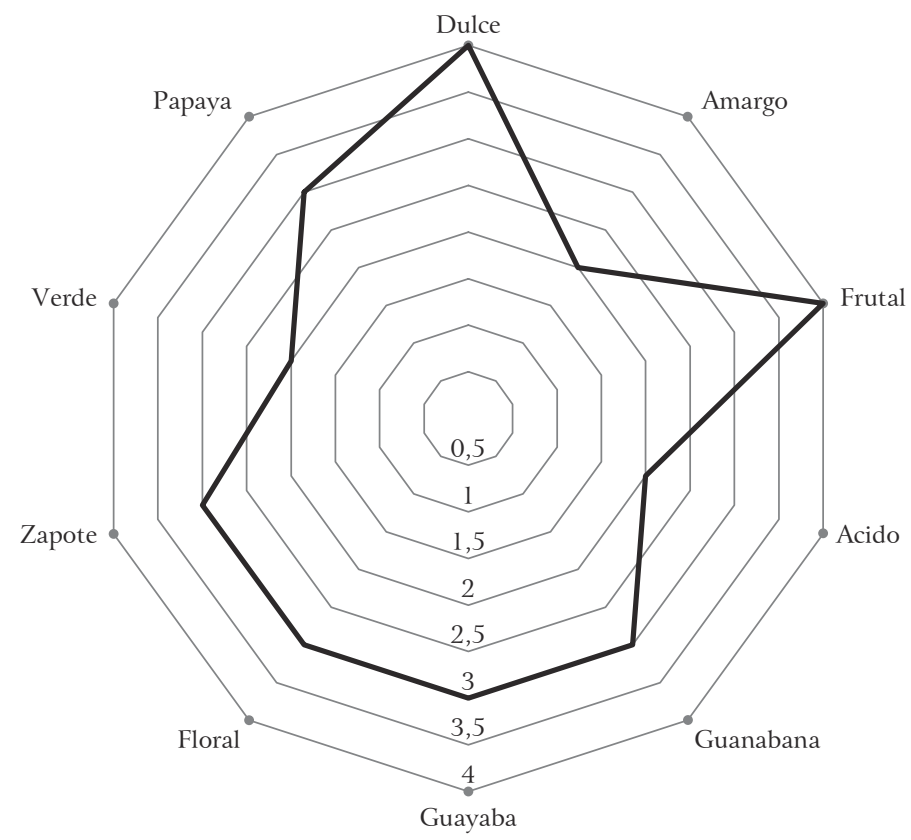

Intensidad

Figura 2 - Perfil de sabor del sietesabores (Diospyros blancoi). 
Se determinó la calidad del fruto utilizando una escala de 1 a 3, en la que $\mathrm{l}$ es bajo y 3 es alto. Para la muestra el valor asignado fue 3 . Finalmente, los jurados determinaron lo siguiente:

"El olor es rico en compuestos volátiles frutales; el primer olor en percibirse es a papaya, además se identifica olor a banano maduro y maracuyá pero este último no se encuentra en el sabor. Se identificaron otros sabores como poma, pera criolla, níspero, piña, que de acuerdo a su baja frecuencia, no se cuantifican. Produce astringencia. Fruto de muy buen sabor."

El análisis indica la multiplicidad de sabores que se corrobora con los hallazgos en campo. No es posible deducir un sabor único pero si es coincidente la información científica con la local, en la cual se percibe la existencia de muchos sabores, reunidos en una sola especie comestible.

\section{CONCLUSIONES}

San Francisco de Asís ostenta una oferta frutícola susceptible de convertirse en una fuente potencial de desarrollo con proyectos sostenibles basados en productos locales. Las preparaciones están respaldadas por un bagaje culinario diverso gracias a la confluencia cultural, que desde su fundación, enriquece sus sabores. Podría pensarse que tal confluencia tendería a una homogenización, generada por la oferta de productos alimenticios estandarizados y la cercanía entre los diferentes grupos. No obstante, las profundas diferencias heredadas de las tradiciones que coexisten en San Francisco de Asís aún garantizan cierta margen de interculturalidad, que respalda la diversidad en las preparaciones y saberes culinarios. La oferta de turismo ecológico y de aventura en región del Darién Caribe propicia la llegada de visitantes, especialmente en las temporadas vacacionales, pero también de investigadores interesados por comprender la realidad ecológica, biológica y cultural de la zona. En palabras de Gálvez (2009: 4), los sabores de la frontera ${ }^{14}$ invitan a "una exploración de la alteridad sensorial desde lo íntimo del acto del comer, que conduce al viajero a otros mundos culturales, a sus cocinas y a sabores inusitados".

La agroecología investiga nuevos mecanismos que permiten trasformar qué producimos y cómo nos alimentamos desde una estrategia de biodiversidad ecológica, cultural y alimentaria (Méndez y Gliessman 2002; Altieri 1999;

14 En la teoría sociológica, el término de frontera trasciende el lugar como territorio físico y delimitación política alejada de los centros de poder, ante todo a los procesos culturales en circulación continua, tanto de personas, como de información, de bienes y servicios, creando comunidades simbólicas y redes de empoderamiento frente al modelo de desarrollo excluyente, que las recoloniza o las subalterniza (Motta 2008). 
Gliessman 2008). La riqueza cultural y biológica que subyace en la región soportaría el desarrollo de modelos agroecológicos; sin embargo, la presión constante de fuerzas opuestas al interés conservacionista ha sido causa de drásticas trasformaciones que amenazan la vigencia de este potencial escenario. Su componente social sufre las consecuencias de los efectos de la economía del narcotráfico, inscrita en procesos de circulación hacia Estados Unidos vía Panamá.

La rápida monetización de la economía de la región ha desplazado la economía de subsistencia basada en la agricultura, la pesca y la cría de especies menores, hacia otra economía dependiente del mercado. Los conocimientos locales en torno a especies frutales del bosque y cultivos de especies fomentadas se quedan huérfanos del relevo generacional que los implementen debido a programas de asistencia gubernamental basados en subsidios en dinero, que debilitan prácticas tradicionales en aras del mejoramiento de la calidad de vida basado en el acceso a dinero en efectivo.

Este conocimiento sobre frutales silvestres relativamente inéditos y algunos endémicos en la región de estudio, y los usos alternativos que las comunidades asentadas en el Darién han perfeccionado, han sido relegados. Quizá uno de los aspectos más notables es que los niños ya no son los consumidores de estos frutos del bosque, actividad que estuvo relacionada con la temprana aproximación a la selva de las generaciones anteriores. Los niños saben que son "una buena comida" y "saludable", pero también la refieren como productos relacionados con "pobreza", lo que conduce a sentimientos de vergüenza e inferioridad cuando son consumidos, dando lugar a cambios en el gusto alimentario, que prefiere las golosinas de origen industrial. Los adultos ya no son participes de ese proceso de enseñanza-aprendizaje, debido a la ausencia de los padres en el procesos de formación, aspecto que ha sido encargado a la escuela formal. Para Atran y Sperber (1991, cit. en Martínez-Rodríguez 2009), la instrucción paterna es un aspecto fundamental en los procesos de instrucción no planificada en la replicación de comportamientos y la observación del contexto natural con el fin de fortalecer la identidad local, hoy erosionada.

Así mismo, los procesos de deforestación para satisfacer la demanda de maderas en el mercado nacional y local ponen en riesgo la existencia de especies florísticas que sólo existen en zonas de bosque húmedo tropical como la región del Darién, hábitat además de la fauna endémica. Este fenómeno favorece la expansión de la frontera agrícola y ganadera que, con el tiempo, ha incrementado la compactación del suelo, afectando su fertilidad y sanidad. Como respuesta al deterioro ecológico, la fauna se ha convertido en depredadora de los pocos cultivos de pancoger que aún existen en las zonas rurales, convirtiéndose en grave amenaza para la subsistencia de los escasos agricultores de la región. 
San Francisco de Asís es víctima de un Estado ausente en su función veedora de proyectos de participación y protección de la ciudadanía y en la aplicación de otros sin la debida planificación y previsión de los efectos lesivos que políticas paternalistas pueden ocasionar en los procesos culturales de las comunidades, en sus costumbres y saberes locales. Las acciones inmediatistas no sólo han marcado la pauta en la desprotección de los recursos naturales aún disponibles en el Darién, sino que además inciden el ámbito propio de comunidades como San Francisco de Asís pervirtiendo su identidad y sus valores. En palabras de Caporal (2009), esto significa que las decisiones colectivas o individuales han afectado y co-evolucionado con el proceso de deterioro ambiental.

Especies silvestres frutales que aún no están incluidas en la tabla de composición de alimentos del Instituto Colombiano de Bienestar Familiar (ICBF) y las fomentadas como el sietesabores y la jagua podrían ser una alternativa para la generación de propuestas económicas sostenibles gestionadas desde las comunidades a partir de conocimientos locales. ${ }^{15}$ Para ello es necesario generar estrategias de comercialización que permitan superar las limitantes económicas resultantes del trasporte desde este territorio geográficamente aislado hacia el interior del país. Sin embargo, esta es una limitante menor ante la necesidad de proyectos que mitiguen la explotación indiscriminada del bosque y reorienten las posibilidades de desarrollo económico de las nuevas generaciones hacia actividades alejadas de la ilegalidad.

15 El ICBF es una entidad adscrita al Departamento para la Prosperidad Social que trabaja por la prevención y protección integral de la primera infancia, la niñez, la adolescencia y el bienestar de las familias en Colombia. Ver < www.icbf.gov.co $>$. 


\section{BIBLIOGRAFÍA}

ALEXIADES, Miguel, 1996, Selected Guidelines for Ethnobotanical Research: A Field Manual. Nueva York, The New York Botanical.

Altieri, M.A. 1999, Agroecología: Bases Científicas para Una Agricultura Sustentable. Montevideo, Editorial Nordan-Comunidad.

ÁLVAREZ-SALAS, Lizeth 2014, "Estudio etnobotánico y agroecológico de plantas promisorias de uso alimenticio del Darién Caribe Colombiano”, Boletín de Antropología, 29 (48): 28-55.

ÁLVAREZ-SALAS, Lizeth, y Aída GÁLVEZ-ABADÍA, 2014, "Food sovereignty in a socioecological transformation context in the Caribbean Darién of Colombia", Agroecology and Sustainable Food Systems, 38 (7): 812-838.

ÁLVAREZ-SALAS, Lizeth, Diana POLANCO-ECHEVERRY, y Leonardo RÍOS-OSORIO, 2014, "Reflexiones acerca de los aspectos epistemológicos de la agroecología", Cuadernos de Desarrollo Rural, 11 (74): 55-74.

ATRAN, Scott, y Dan SPERBER, 1991, "Learning without teaching: its place in culture", en L. Tolchinsky-Landsmann (comp.), Culture, Schooling and Psychological Development. Norwood, NJ, Ablex, 39-55.

BECERRA, Juana, Rodrigo ESCOBAR, y Yesica SERNA, 2004, "Estudio del cultivo bajo cubierta de cuatro especies vegetales de la huerta Chocoana en el municipio de Quibdó, Chocó - Colombia", Revista Institucional Universidad Tecnológica del Chocó, 21: 24-28.

BENSKY, Dan, Steven ClAVEY, y Erich STOGER, 2004, Chinese Herbal Medicine: Materia Medica. Seattle, Eastland Press.

CAICEDO, Emilia, 2004, "Medicina popular", Nueva Revista Colombiana de Folclor, 7 (23): 123-125.

CAPORAL, Francisco Roberto (org.), 2009, Agroecologia: Uma Ciência do Campo da Complexidade. Brasilia, s/ed., disponible en < http://frcaporal.blogspot.pt/p/livros.html > (última consulta en enero del 2016).

CASTRO, Avinxon, Deivis ABADÍA, y Nayibe PINO, 2004, "Plantas silvestres alimenticias de uso tradicional en las comunidades de Pacurita, San José de Purré y Guayabal, municipio de Quibdó, Chocó", Revista Institucional Universidad Tecnológica del Chocó, 18: 37-42.

COLES, Ashley, et al., 2011 , "Mapeo del conocimiento tradicional sobre las amenazas para la investigación aplicada informada, prácticas y políticas en las Américas", Gestión y Ambiente, 14 (2): 45-58.

CRUZ-GARCÍA, Gisella, 2006, "The mother-child nexus: knowledge and valuation of wild food plants in Wayanad, Western Ghats, India”, Journal of Ethnobiology and Ethnomedicine, 2: $39-45$.

DANE - Departamento Administrativo Nacional de Estadística, 2005, Censo General 2005, Base de Datos, disponible en < https://www.dane.gov.co/files/censos/libroCenso2005na cional.pdf $>$ (última consulta en enero del 2016).

FEUILLET, Carolina, Diego MACIAS, y Edith CHITO, 201 1, "Plantas útiles para la elaboración de artesanías en el departamento del Cauca (Colombia)”, Boletín Científico del Museo de Historia Natural, 15 (2): 40-59.

FONNEGRA, Ramiro, Helena BOTERO, y Silvia JIMÉNEZ, 2000, Plantas Utilizadas contra la Mordedura de Serpientes en Antioquia y Chocó, Colombia. Medellin, Editorial Universidad de Antioquia. 
FONNEGRA, Ramiro, Helena BOTERO, y Silvia JIMÉNEZ, 2010, "Plantas mágico-religiosas: historia, mitos y leyendas", Boletín Científico y Cultural del Museo Universitario, 11 (23): 34-55.

FRANCO, Sofía, 1996, Huertas, Azoteas y Plantas no Cultivadas: Un Modelo Antropológico para Determinar Usos Alimentarios entre los Habitantes de los Barrios Populares de Quibdó. Medellín, Medellín Editorial.

GÁlVEZ, Aída, 2009, “De sietesabores y otras delicias: cocinas y turismo en el Darién (Caribe colombiano)”, ponencia en el 53. ${ }^{\circ}$ Congreso Internacional de Americanistas, Ciudad de México, 19-23 de julio.

GARCÍA, Fabio, 2002, "Composición, estructura y etnobotánica de un bosque pluvial tropical (bp-T), en Salero, Chocó”, Revista Institucional Universidad Tecnológica del Chocó, 17 : 3-9.

GARCÍA, Fabio, et al., 2002, "La familia Arecaceae, recurso promisorio para la economía en el departamento del Chocó”, Revista Institucional Universidad Tecnológica del Chocó, 15: 96-101.

GARCÍA, Rolando, 2006, Sistemas Complejos: Conceptos, Método y Fundamentación Epistemológica de la Investigación Interdisciplinaria. Barcelona, Gedisa.

GHANI, Abdul, 1998, Medicinal Plants of Bangladesh: Chemical Constituents and Uses. Dhaka, Asiatic Society of Bangladesh.

GLIESSMAN, Steven, 2008, Agroecology: Researching the Ecological Basis for Sustainable Agriculture. Nueva York, Springer.

GUBER, Rosana, 2007, La Etnografía: Método, Campo y Reflexividad. Bogotá, Grupo Editorial Norma.

HURTADO, Adriana, et al. (coords.), 2008, Análisis Ecorregional para la construcción de un Plan de Conservación de la Biodiversidad en el Complejo Ecorregional Chocó-Darién. Bogotá, WWF Colombia y Fundación Ecotrópico y Cecoin.

LEE, Mei-Hsien, et al., 2006, "Antioxidant and heme oxygenase-1 (HO-1)-induced effects of selected Taiwanese plants", Fitoterapia, 77 (2): 109-115.

LIZANA, Louis, 1990, "Lucuma”, en S. Nagy, P. Shaw y W. Wardowsky (comps.), Fruits of Tropical and Subtropical Origin: Composition, Properties and Uses. Lake Alfred, FL, Florida Science Source, 131-148.

MALINOWSKI, Bronislaw, 1973 [1922], Los Argonautas del Pacífico Occidental. Barcelona, Península.

MARTIN, Gary J., 1995, Etnobotánica: Pueblos y Plantas, Manual de Conservación. Montevideo, Editorial Nordan-Comunidad.

MARTÍNEZ-RODRÍGUEZ, Ruth, 2009, Ethnobotanical Knowledge Acquisition among Tsimane' Children in the Bolivian Amazon. Athens, GA, University of Georgia, tesis de doctorado.

MASCOLO, N., et al., 1989, "Ethnopharmacologic investigation of ginger (Zingiber officinale)", Journal of Ethnopharmacology, 27 (1-2): 129-140.

MENDEZ, Ernesto, y Steven GLIESSMAN, 2002, "Un enfoque interdisciplinario para la investigación en Agroecología y desarrollo rural en el trópico latinoamericano", Manejo Integrado de Plagas y Agroecología (Costa Rica), 64: 5-16.

MOLANO, Alfredo, y Constanza RAMíreZ, 1996, Tapón del Darién: Diario de Una Travesía. Bogotá, El Sello.

MORA-DELGADO, Jairo, 2009, "Persistencia, conocimiento local y estrategias de vida en sociedades campesinas", Revista de Estudios Sociales, 29: 3-17. 
MOTTA, Nancy, 2008, “Territorios de frontera e historias locales: una etnografía multifocal”, Historia y Espacio, 30, disponible en < https://dialnet.unirioja.es/servlet/articulo?co digo $=4015132>$ (última consulta en enero del 2016).

PIERONI, Andrea, y Lisa PRICE (comps.), 2005, Eating and Healing: Traditional Food as Medicine. Nueva York, Haworth Press.

POBAR, Regucivilla, 2003, "Enhancing the use of value-added products from underutilized fruit of the endangered mabolo (Diospyros blancoi) tree", International Journal of Environmental and Rural Development, 4 (1): 100-105.

POLANCO-ECHEVERRY, Diana, Lizeth ÁLVAREZ-SALAS, y Leonardo RÍOS-OSORIO, 2015, "Proposed methodology for research into the socioecological resilience of agroecosystems", Tropical and Subtropical Agroecosystems, 18 (2): 207-219.

RAGASA, Consolacion, et al., 2009, "Bioactive triterpenes from Diospyros blancoi", Natural Product Research, 23 (13): 1252-1258.

RÍOS, Leonardo, y Alejandro MESA, 2009, Introducción al Pensamiento Científico en Microbiología. Medellín, Corporación para la Investigación Biológica.

ROLDAN, Carlos, 2012, "Lineamientos para la planeación del turismo sostenible en el corregimiento de San Francisco de Asís (Municipio de Acandí, Chocó, Colombia)”, Revista Gestión y Ambiente, 15 (1): 129-142.

RUIZ-SERNA, Daniel, 2006, Nuevas Formas de Ser Negro: Consideraciones sobre las Identidades entre la Gente Chilapa y Negra del Bajo Atrato Chocoano. Caracas, Programa Cultura, Comunicación y Transformaciones Sociales, CIPOST, FaCES, Universidad Central de Venezuela, colección Monografías, n. ${ }^{\circ} 37$.

SALAZAR ZAPATA, Julio, 2012, San Pacho: Una Tierra para la Libertad. Experiencia Ecológica en el Darién Caribe Colombiano. Madrid, Editorial Académica Española.

SETALAPHRUK, Chantita, y Lisa Leimar PRICE, 2007, “Children's traditional ecological knowledge of wild food resources: a case study in a rural village in Northeast Thailand", Journal of Ethnobiology and Ethnomedicine, 3 (33), disponible en < https://ethnobiomed.bio medcentral.com/articles/10.1186/1746-4269-3-33 > (última consulta en enero del 2016).

SHARMA, O.P., R. K. DAWRA, y H.P.S. MAKKAR, 1987, “Isolation and partial purification of Lantana camara toxins", Toxicology Letters, 37 (2): 165-172.

SINCLAIR, Fergus L., y Daniel H. WALKER, 1999, "A utilitarian approach to the incorporation of local knowledge in agroforestry research and extension", en L.E. Buck, J. P. Lassoie y E. C. M. Fernandes (comps.), Agroforestry in Sustainable Agricultural Systems. Nova Iorque, CRC Press, 245-276.

SOMNASANG, P., P. RATHAKETTE, y S. RATHANAPANYA, 1987, "The role of natural foods in Northeast Thailand”, en S. Subhadira, G. Lovelace y S. Simarap (comp.), Rapid Rural Appraisal in Northeast Thailand: Case Studies. Khon Kaen, Khon Kaen University, 78-103.

TURBAY, Sandra, 2004, “Técnicas etnográficas útiles para los estudios socio-económicos y ambientales en bosques tropicales”, Utopía Siglo XXI, 2 (10): 28-43.

UN/PRC - Naciones Unidas, y Presidencia de la Republica de Colombia, 2007, Informe Ejecutivo sobre el Seguimiento a los Programas de Familias Guardabosques y Proyectos Productivos: Monitoreo, Seguimiento y Evaluación al Desarrollo Alternativo en Colombia, disponible en < https://www.unodc.org/documents/colombia/2013/Agosto/DA2013/Informe_ejecutivo_2007_espanol.pdf > (ultima consulta en enero del 2016). 
URIBE, Fernando, et al., 1999, Caracterización Ambiental del Darien: Dimensión Ecológica. Medellín, Centro de Investigaciones en Ciencias Humanas, Universidad de Antioquia y Fundación Natura, inédito.

ZERDA, Álvaro, 2003, Derechos de Propiedad Intelectual del Conocimiento Vernáculo: Análisis y Propuesta desde la Economía Institucionalista. Bogotá, Universidad Nacional de Colombia. ZuluAGA, Germán, 2002, La Botella Curada: Un Estudio de los Sistemas Tradicionales de Salud en las Comunidades Afrocolombianas del Chocó Biogeográfico. Cundinamarca, Amazon Conservation Team. 